\title{
Construção depacientiva em georgiano
}

\author{
Priscila Lima Pirini \\ Universidade de São Paulo (USP), São Paulo, São Paulo, Brasil \\ priscila.pirini@usp.br
}

DOI: http://dx.doi.org/10.21165/el.v46i1.1515

\begin{abstract}
Resumo
Este artigo visa analisar e discutir as construções que chamamos de depacientivas no georgiano (língua sul caucasiana), de forma a contrastá-las com construções circundantes na língua, isto é, construções mais canônicas ou que possuem semelhanças em termos semânticos ou de forma. Argumenta-se, ainda, que as construções depacientivas constituem um fenômeno de voz, isto é, uma forma distinta de se conceitualizar eventos. Como fundamentação teórica, será utilizada a Gramática Cognitiva de Langacker (2008).
\end{abstract}

Palavras-chave: georgiano; construção depacientiva; Gramática Cognitiva.

\section{Depatientive construction in Georgian}

\begin{abstract}
This paper aims to analyze and discuss what we call depatientive constructions in Georgian (South Caucasian language); in order to contrast them with other related constructions in the language, i.e., more canonical constructions or those related by semantic or formal means. It is also argued that the depatientive construction is a voice phenomenon, i.e., a distinct way of conceptualizing events. The analysis presented here is based on the theoretical framework known as Cognitive Grammar (LANGACKER, 2008).
\end{abstract}

Keywords: Georgian; depatientive construction; Cognitive Grammar.

\section{Introdução}

Iniciaremos a argumentação introduzindo os conceitos de construção depacientiva, voz gramatical e construal no quadro teórico utilizado, a Gramática Cognitiva de Langacker. Em seguida, daremos início à discussão que visará caracterizar a construção depacientiva. Para isso, começaremos discutindo sua relação com as construções circundantes, como a construção transitiva, passiva e com alguns dos significados da voz média.

Neste texto, os dados utilizados do georgiano, em que a presente análise foi baseada, foram retirados dos autores estudados e referidos ao longo do texto.

\section{A construção depacientiva}

Seguindo Tuite (2002), os verbos chamados de depoentes em georgiano são aqueles que, de um ponto de vista morfológico, comportam-se como verbos regulares passivos, mas que, de um ponto de vista semântico, possuem uma interpretação ativa. Os verbos depoentes pertenceriam, assim, aos chamados verbos passivos prefixais, que são aqueles formados ou derivados a partir da vogal pré-radical $-i$ - em adição ao sufixo temático -eb-. No entanto, não possuem uma semântica passiva típica de verbos passivos 
da mesma classe, como é esperado, comportando-se, semanticamente, como verbos ativos, isto é, o sujeito não é paciente, mas sim agente da ação.

Observe os exemplos em (01) e (02) a seguir. Em ambos, há a ausência do objeto direto - o exemplo (01) ilustra a agramaticalidade de se adicionar à estrutura um objeto direto 'mtavroba'. Estruturalmente, são verbos de morfologia passiva; note a presença da vogal pré-radical $-i$ - e do sufixo temático $-e b$.

$\begin{array}{lll}\text { is } & \text { i-gin-eb-a } & (\text { *mtavroba-s) } \\ \text { 3sg-nom } & \text { vpr-xingar-st-3sg.nom } & \text { governo-dat } \\ \text { 'Ele fica xingando, está ocupado em xingar ( } & \text { *o governo).' (AMIRIDZE, 2006) }\end{array}$

$$
\begin{array}{ll}
\text { chvil-i } & \text { i-k'bin-eb-a } \\
\text { criança-nom } & \text { vpr-morder-st-3sg.nom } \\
\text { 'A criança morde.' (AMIRIDZE, 2006) }
\end{array}
$$

Em comparação à construção ativa ou mesmo passiva, construções como essa geram uma mudança de foco para a ação em si e sua relação com o sujeito, de modo a chamar a atenção para o comportamento do próprio sujeito (cf. TUITE, 2007). Lichtenberk (2007), que descreveu construção similar em to'aba'ita (uma língua austronésia), chamou esse tipo de construção de depacientiva, termo que optamos manter neste texto para nos referirmos à construção descrita acima e ilustrada em (01) e (02).

Em (03) e (04), é possível contrastar as construções acima com seus correspondentes ativos; atente para a presença do objeto direto e da morfologia distinta:

$$
\begin{array}{lll}
\text { is } & \text { a-gin-eb-s } & \text { mtavroba-s } \\
\text { 3sg-nom } & \text { vpr-xingar-st-3sg.nom } & \text { governo-dat }
\end{array}
$$

'Ele xinga o governo.' (AMIRIDZE, 2006)

$$
\begin{array}{ll}
\text { chvil-i } & \text { m-k'en-s } \\
\text { criança-nom } & 1 \text { sg.dat-morder.3sg.nom } \\
\text { 'A criança me morde.' }
\end{array}
$$

\section{Voz gramatical}

A variedade observada nos fenômenos de voz encontrados nas línguas reflete a multiplicidade de estratégias que podem ser exploradas e usadas pelos falantes na conceitualização de eventos.

Woods $\left(2008\right.$, p. 7, tradução nossa ${ }^{1}$ ), em seu livro sobre os prefixos de conjugação do sumério, descreve voz gramatical e sua relação com os prefixos sumérios nos seguintes termos:

\footnotetext{
${ }^{1}$ Broadly described, grammatical voice systems provide speakers with a series of linguistic options for expressing distinct conceptualizations of experience and reality. This is precisely the role played by the Sumerian conjugation prefixes: providing the Sumerian speaker with the linguistic means to express alternative perspectives on events.
} 
Descritos de forma geral, os sistemas de voz gramatical proporcionam aos falantes uma série de opções linguísticas para expressar conceitualizações distintas de sua experiência e realidade. Esse é precisamente o papel desempenhado pelos prefixos de conjugação sumérios: proporcionam ao falante sumério os meios linguísticos para expressar perspectivas alternativas dos eventos.

Compartilhando essa visão, acredita-se que a construção que temos chamado aqui de depacientiva constitui, particularmente, uma estratégia de voz, isto é, uma maneira de expressar uma conceitualização distinta dos eventos. Por essa perspectiva, a vogal préradical - $i$ - - a priori, apropriada de outras construções na língua - de forma semelhante aos prefixos do sumério, estaria servindo para codificar ou marcar linguisticamente a distinção em significação.

Antes de adentrarmos nessa discussão - a construção depacientiva e sua relação com a noção de voz gramatical como maneira de se conceitualizar eventos de formas alternativas e, assim sendo, sua relação com construções circundantes também envolvendo voz -, serão apresentados alguns conceitos provenientes da Gramática Cognitiva (doravante CG) que serão relevantes para a discussão.

\section{Construal na Gramática Cognitiva de Langacker}

Nesta seção, será introduzida a noção de construal da Gramática Cognitiva de Langacker, dada sua importância na caracterização do contraste oferecido por esses conjuntos de diferentes construções.

Construal é nossa habilidade de construir uma mesma situação de modos distintos. Duas expressões podem evocar o mesmo conteúdo conceitual, porém diferir em como esse conteúdo conceitual é construído. Dessa forma, não basta descrever o significado de uma expressão com base apenas no seu conteúdo conceitual; o modo como esse conteúdo é construído é fundamental para sua caracterização plena.

Uma dimensão de construal que particularmente nos interessa é a de proeminência ou saliência. A noção, na CG, envolve nossa habilidade cognitiva de dirigir ou focar a atenção em diferentes elementos ou aspectos de uma situação. Dois tipos de proeminência são de interesse para a descrição das classes marginais sob foco, profiling e alinhamento de trajetor e marco.

Em relações de profiling, perfil, é a estrutura ou referente que uma expressão designa dentro de sua base conceitual, isto é, o conteúdo evocado. O perfil, dessa forma, é a estrutura mais saliente em referência à base, isto é, o elemento ao qual se dirige ou no qual se foca a atenção. Por essa razão, uma expressão pode evocar o mesmo conteúdo e diferir apenas naquilo que é perfilado.

Há expressões, no entanto, em que tanto o conteúdo, ou base conceitual, quanto o perfil são idênticos, nesses casos, a diferença semântica entre essas expressões reside em alinhamentos de trajetor e marco distintos. $\mathrm{Na} C \mathrm{C}$, classes gramaticais como verbo e substantivo são definidas semanticamente, assim, um verbo, em contraste com um substantivo, é definido como aquele que perfila uma relação. Alinhamento de trajetor e marco é o tipo de assimetria, em termos de proeminência, que se observa entre os participantes de uma relação perfilada por um verbo. O participante focal primário, o mais 
saliente e sobre o qual se fala ou descreve, é chamado de trajetor. O participante focal secundário, quando presente, é chamado de marco.

\section{Discussão}

Para caracterizarmos a construção depacientiva como uma forma alternativa de se construir eventos, começaremos a análise discutindo sua relação com construções circundantes, como a construção transitiva, passiva e com alguns dos significados da voz média.

Em comparação com a construção passiva em georgiano, formada, como mencionado, pela vogal pré-radical $-i$-, a construção ativa na língua pode ser considerada como a menos marcada. Por essa perspectiva, relativamente à construção ativa, a vogal pré-radical - $i$ - estaria marcando, linguisticamente, uma alternativa distinta de codificação do evento.

A construção ativa ou voz ativa é aquela que seleciona o agente como o mais proeminente em uma interação entre agente e paciente, em que o evento é visto como uma cadeia de ação, envolvendo transmissão de energia entre agente e paciente de forma que este último sofre os efeitos da mudança induzida pelo agente. $\mathrm{O}$ agente, portanto, seria o ponto inicial de acesso mental do evento.

Essa estratégia de se conceitualizar o evento pode ser observada nos exemplos (03) e (04) com os verbos 'xingar' e 'morder'; ambos envolvem a conceitualização de uma cadeia de ação em que há transmissão de energia entre agente e paciente, o agente é a fonte de energia dessa cadeia de ação e o primeiro elemento a ser acessado, constituindo o foco primário, nos exemplos, os nominais no nominativo 'ele' e 'criança'. O paciente nos exemplos, os nominais no dativo 'governo' e 'me' -, por sua vez, sofre a mudança imposta pelo agente, ainda que metafórica.

A Figura 1 ilustra o diagrama da construção transitiva. Observe que todo o processo é perfilado, do ponto inicial, o agente e foco primário (trajetor), ao fim, o paciente e foco secundário (marco).

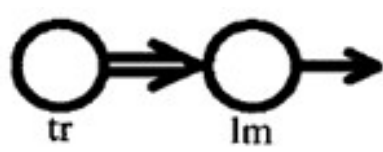

Figura 1. Construção transitiva ativa (LANGACKER, 2008, p. 385)

Relativamente a essa codificação canônica, a construção passiva se destaca por oferecer um construal distinto do mesmo evento. Na construção passiva, o tema é escolhido como foco primário ou trajetor do processo. O agente do processo e fonte de energia é apenas uma entidade implícita ou pressuposta, podendo não ser codificado ou ser codificado perifrasticamente por meio de uma posposição.

Um exemplo de construção passiva no georgiano com a vogal pré-radical $-i$ - pode ser observado em (05). Nesse exemplo, em particular, o verbo passivo em -eb está em sua forma relativa, isto é, na presença de um objeto indireto no dativo kal-s 'mulher', a vogal pré-radical - $i$ - nesse verbo foi substituída pela vogal pré-radical - $e$ - que marca a presença do argumento extra. De qualquer forma, a sentença exemplifica uma construção passiva típica na língua, em que o foco primário é deslocado para o tema pul-i 'dinheiro', 
omitindo-se o agente da ação do processo perfilado, ou seja, aquele que dá o dinheiro, a fonte de energia.
kal-s
pul-i
e-dzlev-a
mulher-dat
dinheiro-nom
vpr-dar-3sg.nom
'Dinheiro está sendo entregue à mulher.' (TUITE, 2007)

A Figura 2 representa o diagrama da construção passiva, em que apenas o tema recebe status de participante focado, constituindo o foco primário.

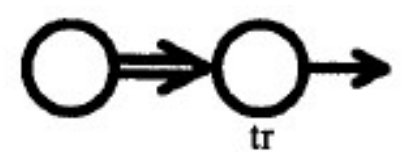

Figura 2. Construção passiva (LANGACKER, 2008, p. 385)

Em contraste a essas duas vozes gramaticais, a função da voz média, segundo Maldonado (2007), estaria em focar no próprio domínio do sujeito, isto é, denotaria eventos ou estados pertencentes à própria esfera do sujeito. Mais especificamente, para o autor:

A função central da voz média é focar na mudança de estado sofrida pelo sujeito (Maldonado, 1992, 1999). Em outras palavras, já que a marca de voz média impõe uma conceitualização centrada no sujeito, crucialmente acaba perfilando a mudança de estado observável. (MALDONADO, 2007, p. 856, tradução nossa² ${ }^{2}$.

Dentre os eventos prototípicos associados à voz média, estão os 'tipos de situação' identificados por Kemmer (1994) como aqueles usualmente marcados pela construção média, por exemplo: eventos de cuidados corporais, envolvendo elementos dentro do domínio do sujeito, tais como partes do corpo e posse inalienável; eventos de mudança de postura corporal do sujeito e mudança de lugar, acarretando alguma transmissão de energia interna; eventos envolvendo mudanças internas, mentais ou emocionais; etc. (MALDONADO, 2007).

Nessas situações típicas da voz média, os efeitos da ação denotada pelo verbo recaem, de um modo ou de outro, sobre o próprio sujeito ou sobre seu domínio, por essa razão, o evento gira em torno daquele único participante. Como observa Maldonado (2007), a construção média frequentemente se sobrepõe às construções intransitivas, já que ambas envolveriam um participante. Esse dado é particularmente interessante se pensarmos que, no georgiano e em outras línguas (por exemplo, to'aba'ita e russo), a mesma marca morfológica parece codificar construções associadas à intransitividade, como construções passivas, médias e depacientivas. Em georgiano, notoriamente, essa marca é a vogal pré-radical $-i$ -

Devido ao foco, na construção média, recair em seu único participante, haveria um maior grau de não distinguibilidade, ou não diferenciação, entre participantes, isto é, entre sujeito e objeto afetado. Por essa razão, Kemmer (1994) posiciona a voz média entre

\footnotetext{
${ }^{2}$ [The middle voice] core function is to focus on the change-of-state undergone by the subject (Maldonado 1992, 1999). In other words, since the middle marker imposes a conceptualization centered on the subject, it crucially profiles the observable change-of-state. (MALDONADO, 2007, p. 856).
} 
eventos de dois participantes e de um participante, havendo uma diminuição gradual de distinção de participantes entre um ponto (dois participantes) a outro (um participante). Nesse aspecto, a construção reflexiva contrastaria com a construção média, já que, ao contrário da construção média em que não há diferenciação de participantes, o sentido reflexivo implicaria correferencialidade entre sujeito e objeto, isto é, um único participante ocuparia os papéis de trajetor e marco (LANGACKER, 2008; MALDONADO, 2007).

O diagrama da Figura 3 representa a construção média, envolvendo um evento que ocorre dentro do domínio do próprio sujeito:

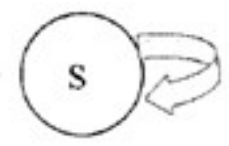

Figura 3. Construção média (MALDONADO, 2007)

Em georgiano, embora não haja uma construção específica que marque os significados usualmente associados à voz média, é interessante observarmos aqui algumas similaridades, já notadas na literatura da língua, entre os significados da voz média e, em específico, a versão subjetiva (marcada pela vogal pré-radical -i-).

Tuite (2007) aponta algumas semelhanças entre a descrição da semântica frequentemente atribuída à voz média àquela da versão subjetiva, por exemplo, denotar eventos que acontecem em benefício do sujeito ou de sua posse. Em particular, alguns grupos de verbos - destacados pelo autor e formados pela vogal pré-radical - $i$ - ou, mais especificamente, pela versão subjetiva - corresponderiam a alguns dos significados relacionados à construção média ${ }^{3}$.

Dentre eles, estão certos verbos ativos que teriam a versão subjetiva como formação não marcada, isto é, não teriam formas correspondentes com a versão neutra ou objetiva. Segundo Tuite (2007), esses verbos teriam uma semântica consistente, em que a ação denotada pelo verbo seria orientada para o sujeito, a maior parte aglomerando-se ao redor das situações de tipo descritas por Kemmer (1994) como 'média indireta', por exemplo, o verbo $v$-i-dzen 'eu procuro, obtenho' e 'média cognitiva', por exemplo, o verbo ga-v-i-geb 'eu entenderei' (TUITE, 2007).

Outros verbos seriam certos verbos ativos com a versão subjetiva, por exemplo, $v$ - $i$-p 'ars- $a v$ 'eu me barbeio' correspondendo à situação de tipo de Kemmer (1994) referente a cuidados corporais; e uma parte considerável de verbos tradicionalmente classificados como de Classe III (intransitivos agentivos), por exemplo, $v$ - $x t$ 'una-ob 'eu pulo para cima e para baixo' (fut: $v$-i-xt'unav-eb) correspondendo à situação de tipo de 'movimento translacional' de Kemmer e $v$-c'k'mut'un-eb 'eu choramingo' (fut: $v-i$ c'k'mut'un-eb), correspondendo à situação de 'ações de fala emotiva' (TUITE, 2007).

No georgiano moderno, a vogal pré-radical - $i$ - apenas está presente nas formas do futuro e do aoristo de verbos intransitivos agentivos. Seu aparecimento, nesses tempos, é um desenvolvimento posterior a partir de empréstimo de outros paradigmas verbais télicos, o que parece também ter motivado a maior sobreposição da versão subjetiva nesses grupos de verbos com a voz média (TUITE, 2007).

\footnotetext{
3 Tuite (2007) atenta, por exemplo, para a similaridade semântica entre o verbo ativo com versão subjetiva $i$-xsn-i-s 'soltar, desatar' e o verbo na voz média do grego $\lambda v \varepsilon-\tau \alpha l$ 'soltar, desatar para si mesmo'.
} 
Diante dessas considerações, é possível perceber que, ainda que o georgiano não possua uma construção específica para marcar a voz média, há correlações e similaridades entre os significados usualmente atribuídos à voz média e o uso da vogal pré-radical $-i-$. Mais notavelmente, o ponto a ser argumentado a seguir é que a mesma marca em georgiano, associada aos significados da voz média, venha a marcar também a construção depacientiva sob foco.

Essa correlação entre a marcação das duas construções não é exclusiva do georgiano. Na língua to'aba'ita, a mesma marca encontrada na construção depacientiva também é observada em construções com significados atribuídos à voz média. Mais do que mera coincidência, acreditamos que a correlação em marcação entre as duas construções se dá por certas similaridades conceituais entre os diferentes construals por elas codificados.

As construções ativas transitivas em (03) e (04) que, nos termos da CG, codificam o modelo de evento canônico - isto é, uma interação entre agente e paciente, em que o primeiro induz uma mudança de estado no segundo -, se tomadas como a construção não marcada relativamente, por exemplo, à construção passiva, podem ser consideradas a base para a derivação também de construções como a depacientiva, mais marcada. Isso tanto em termos de significado, já que, acredita-se, constitui uma alternativa de se conceitualizar esse evento canônico, quanto em termos de forma, isto é, no uso da vogal pré-radical $-i$-.

Nos exemplos de construções depacientivas com verbos de base transitiva, fornecidos em $(01)$ e (02), há o apagamento do paciente relativamente à construção equivalente transitiva. Observe que tanto em (01) quanto (02) - em contraste com (03) e (04) respectivamente - o tema, constituindo o foco secundário, o marco, é apagado: a entidade à qual é dirigido o xingamento em (01), e quem ou o que é mordido em (02).

O resultado são eventos de um argumento que, sendo o único participante focado, passa, consequentemente, a receber proeminência máxima, isto é, é o foco primário, o trajetor. Como ressalta Langacker (2008), a própria ausência de um argumento já resulta em uma maior saliência do participante restante, visto que se anula a competição entre participantes.

Mesmo em verbos normalmente usados intransitivamente como i-cingl-eb-i 'choramingar', $i-q$ 'ep-eb-a 'latir', $i-p$ 'ranch-eb-a 'fazer pose/graça', o efeito ou resultado do seu uso na construção depacientiva é o mesmo de verbos de base transitiva. $\mathrm{O}$ único participante recebe proeminência máxima, denotando um evento muito mais marcado semanticamente do que o correspondente intransitivo ativo, semanticamente menos marcado (cf. a-purtx-eb-s 'cuspir', q'ep-s 'latir' e p'ranch'-av-s 'fazer graça, flertar') (TUITE, 2002).

Como consequência, a construção depacientiva, em todos esses exemplos, tem como efeito, em contraste com a construção ativa, deslocar o foco para os contornos da ação denotada pelo verbo e para o sujeito como agente daquela ação. Essa mudança de foco acarreta eventos semanticamente mais marcados, isto é, há uma maior caracterização desse evento em termos de sua aparência ou impressão causada nos outros, ou seja, tal como é percebido pelo observador, sendo orações usualmente proferidas na segunda e terceira pessoas. 
Por essa razão, essas construções não raramente apontam para o comportamento inapropriado, desagradável ou inconveniente do sujeito, ocasionando uma impressão negativa por parte do observador. Ademais, frequentemente enfatizam a natureza repetitiva ou habitual de certas ações, às vezes, como ações características do sujeito por exemplo, os verbos depacientivos $i$-coxn-eb-a 'mastigar', $i$-k'bin-eb-a 'morder'e $i$ q'ep-eb-a 'latir', denotando eventos de natureza repetitiva ou que são característicos daquele sujeito, isto é, como possuidor aquela propriedade (TUITE, 2002).

Devido ao foco estar na natureza da ação e no próprio agente que a pratica, os eventos comumente denotados nessas construções referem-se, segundo Tuite (2002), a comportamentos que chamam a atenção do observador por sua aparência ou conveniência, abarcando verbos que expressam ações comportamentais como comer (e.g., $i$-coxn-eb-a 'mastigar'), olhar ( $i$-ch'qit'-eb-a 'olhar estupefato'), contato corporal (i-k'bin-eb-a 'morder'), expressões faciais (i-ghmich'-eb-a 'contorcer a face em desagrado'), atitudes ou comportamentos (i-p'ranch'-eb-a 'fazer graça, flertar'), atos de fala (i-landzgh-eb-a 'insultar'), etc. (TUITE, 2002).

Devido a essa saliência atribuída ao agente, ele constituiria o ponto de início de acesso mental, tanto do ponto de vista de proeminência, como trajetor, quanto da orientação, considerando o fluxo de energia numa cadeia de ação, como agente. Da mesma forma, na construção ativa, o evento é evocado como uma cadeia de ação, envolvendo transmissão de energia entre agente e um tema. No entanto, diferentemente da construção ativa que perfila todo o evento, de seu início da cadeia de ação (o agente) ao seu resultado (o processo temático), a construção depacientiva evoca o processo temático apenas de forma esquemática (observe a Figura 4), não constituindo um participante focado, isto é, não é codificado linguisticamente. Na construção depacientiva, apenas o início da cadeia de ação é perfilado e codificado, ou seja, o agente e a ação por ele praticada.

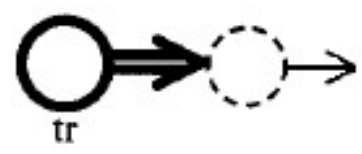

Figura 4. Construção depacientiva

Desse modo, acredita-se que a construção depacientiva constitui uma alternativa de conceitualização de eventos relativamente à construção ativa, sendo marcada linguisticamente pela vogal pré-radical - $i$-. Argumenta-se, no entanto, que a apropriação da vogal pré-radical - $i$ - para marcar a construção depacientiva constitui não somente uma forma de os falantes utilizarem os próprios recursos oferecidos pela língua para atribuir novas significações, mas também uma aproximação aos sentidos associados ou marcados pela vogal pré-radical -i-, dentre eles, aqueles associados à voz média, as duas, possivelmente, sendo extensões da versão subjetiva em georgiano.

Pela exposição que fizemos dos sentidos atribuídos tanto à construção depacientiva quanto aos da voz média, é possível traçar algumas similaridades semânticas entre as duas construções, argumentando-se que, assim como a construção média, a construção depacientiva também envolve certo foco no domínio do sujeito.

Como foi visto, na construção média, a ação permanece dentro da própria esfera do sujeito, isto é, é dirigida a ele e não a outro participante, afetando o sujeito ou seus interesses. Na construção depacientiva, ainda que a ação não se volte ou afete o sujeito, 
é, às vezes, uma ação característica daquele indivíduo, como a denotar uma propriedade do agente. Esse significado, ainda que não constitua uma ação que afete ou se volte ao sujeito, parece, em menor grau, estar dentro do domínio do sujeito, tornando, por esse motivo, a codificação do tema irrelevante ou genérica, isto é, sendo evocado apenas de forma esquemática. Daí, portanto, surge a semelhança, tanto no que se refere à conceitualização de eventos que evocam, quanto no que diz respeito à formação, nesse caso, a vogal pré-radical - $i$ -

Em termos de formação de um continuum de construções, de um lado, haveria a construção transitiva ativa com dois participantes, perfilando toda a cadeia de ação, isto é, a interação entre agente e paciente, do outro, haveria a construção média que envolve apenas um participante, focando no domínio do sujeito, a ação referindo-se ou o afetando de certa forma. No meio dessas duas construções, surge a construção depacientiva que, embora evoque conceitualmente toda a cadeia de ação, apenas um participante é focado, o agente, o processo temático sendo evocado apenas esquematicamente, isto é, a construção depacientiva perfilaria somente o agente como fonte de energia e a ação por ele desencadeada.

Por esse lado, a construção depacientiva se aproximaria da construção ativa ao evocar, ainda que esquematicamente, toda a cadeia de ação. Por outro, se aproximaria de uma construção média, com um participante e focando no domínio do sujeito, característica esta que acreditamos, ainda que de forma mais branda, também está presente na significação da construção depacientiva.

Argumenta-se ainda que as duas construções em georgiano, média (ou os sentidos associados a ela) e depacientiva, constituem possivelmente extensões dos sentidos associados à vogal pré-radical $-i-$, principalmente, em relação ao seu sentido como versão subjetiva em georgiano.

Com base na CG, considera-se que lexemas verbais são aprendidos no contexto das construções que aparecem e vice-versa, isto é, por meio de arraigamento e convencionalização do uso de um lexema verbal em determinada construção, é possível dizer que o verbo possui o sentido associado àquela construção. Ou seja, o significado associado à construção passa a fazer parte do network de construções, ou sentidos, associadas ao lexema verbal. ${ }^{4}$

Assim como um lexema verbal, um item dito gramatical, como as vogais préradicais, também é aprendido no contexto das construções em que convencionalmente aparece. $\mathrm{O}$ significado daquela construção passa a fazer parte do network de sentidos associados àquele morfema ou item gramatical. É importante salientar que, na CG, léxico e gramática formam um continuum, diferindo apenas em termos de complexidade simbólica.

Dessa forma, a descrição de uma unidade linguística, como a vogal pré-radical $i$, depende da descrição do conjunto de frames estruturais em que convencionalmente aparece uma dimensão de sua complexidade sendo, portanto, sua ocorrência em contextos

\footnotetext{
${ }^{4} \mathrm{Na} \mathrm{CG}$, unidades linguísticas convencionais são rotinas cognitivas arraigadas, convencionais à medida que são padrões linguísticos estabelecidos em dada comunidade linguística, e arraigadas, dada a frequência em que são usadas, isto é, quanto mais frequentemente forem usadas ou expostas ao falante, maior o grau de arraigamento dessas unidades.
} 
estruturais maiores. Nas palavras de Langacker (2008, p. 241, tradução nossa ${ }^{5}$ ) "até certo ponto, o significado do lexema é moldado pelos frames em que ocorre". Ademais, como Gurevich (2006) ressalta, o sentido de uma vogal pré-radical somente pode ser definido dentro de contextos morfossintáticos maiores, nos termos da $\mathrm{CG}$, no contexto das construções em que aparece.

Por essa perspectiva, através de arraigamento e convencionalização, os significados associados a construções em que a vogal pré-radical - $i$ - aparece - como, dentre outras, a construção passiva - tem seu uso como versão subjetiva. Como acreditamos, a construção depacientiva e as construções com sentidos associados à voz média fazem parte do network de sentidos associados à vogal pré-radical $-i$-, cada qual a formar, portanto, esquemas abstraídos de similaridades apreendidas entre diferentes instâncias.

Supõe-se, em particular, que as construções com sentidos associados à voz média e construções depacientivas marcadas pela vogal pré-radical $-i$ - sejam, possivelmente, extensões do já bastante arraigado e produtivo esquema construcional de seu uso como versão subjetiva, partindo-se de similaridades semânticas entre as construções e a formar construções com diferentes significados.

\section{Considerações finais}

Neste texto, a partir da análise dos dados do georgiano, foi apresentado o que chamamos de construção depacientiva. Com o intuito de caracterizar a construção depacientiva, partindo da hipótese de que constitui um fenômeno de voz na língua, procuramos caracterizar essa construção discutindo, dentro da Gramática Cognitiva, sua relação com outras construções na língua, como a construção transitiva, passiva e com alguns dos significados da voz média.

Ao fim, demonstramos que a construção depacientiva, tal como outras construções mais canônicas na língua, representa um meio alternativo de se construir eventos, isto é, constitui uma forma distinta de conceitualização.

No evento codificado pela construção depacientiva, diferentemente da construção ativa que perfila todo o evento, de seu início da cadeia de ação ao seu resultado, o processo temático é evocado apenas de forma esquemática. Na construção depacientiva, portanto, somente o início da cadeia de ação é perfilado e codificado, isto é, o agente e a ação por ele praticada.

\section{REFERÊNCIAS}

AMIRIDZE, N. Reflexivization strategies in Georgian. 2006. 332 f. Thesis (Ph.D) Universiteit Utrecht, 2006.

GUREVICH, O. I. Constructional Morphology: The Georgian Version. 2006. $257 \mathrm{f}$. Thesis (Ph.D) - University Of California, Berkeley, 2006.

KEMMER, S. The Middle Voice. Typological Studies in Language 23. Amsterdam: John Benjamins, 1993.

\footnotetext{
${ }^{5}[\ldots]$ to some extent, a lexeme's meaning is shaped by the frames it occurs in.
} 
. Middle voice, transitivity and events. In: FOX, B.; HOPPER, P. (Eds.). Voice: Form and Function. Amsterdam: John Benjamins, 1994. p. 179-230.

LANGACKER, R. W. Foundations of Cognitive Grammar. v. 1: Theoretical Prerequisites. Stanford: Stanford University Press, 1987.

. Foundations of Cognitive Grammar. v. 2: Descriptive Application. Stanford: Stanford University Press, 1991.

Grammar and Conceptualization. Cognitive Linguistics Research 14. Berlin: Mouton de Gruyter, 1999. 2008. Cognitive Grammar: A Basic Introduction. New York: Oxford University Press,

LICHTENBERK, F. Reciprocals and related meanings in To'aba'ita. In: NEDJALKOV, V. P. (Ed.). Reciprocal constructions. Amsterdam/Philadelphia: John Benjamins Publishing Company, 2007. p. 1547-1571. 5 volumes.

MALDONADO, R. Grammatical Voice in Cognitive Grammar. In: CUYCKENS, H.; GEERAERTS, D. (Eds.). The Oxford Handbook of Cognitive Linguistics. New York: Oxford University Press, 2007. p. 829-868.

TUITE, K. Kartvelian Morphosyntax. Number agreement and morphosyntactic orientation in the South Caucasian languages. (Studies in Caucasian Linguistics, 12). München: Lincom Europa, 1998.

. Deponent verbs in Georgian. Philologie, Typologie und Sprachstruktur: Festschrift für Winfried Boeder zum 65. Geburtstag, Wolfram Bublitz, Manfred von Roncador, Heinz Vater (Ed.). Frankfurt am Main: Peter Lang Verlag, 2002. p. 375-389.

Liminal morphosyntax: Georgian deponents and their kin. Chicago Linguistics Society, v. 39, p. 774-788, 2007.

WOODS, C. The Grammar of Perspective: The Sumerian Conjugation Prefixes As a System of Voice. Cuneiform Monographs. v. 32. Leiden: Brill, 2008.

Recebido em: 09/08/2016

Aprovado em: 27/03/2017 